\title{
SURFACE STRUCTURE AND PROPERTIES OF CALCIUM HYDROXYAPATITE PARTICLES MODIFIED WITH PYROPHOSPHORIC ACID
}

\author{
HIDEKAZU TANAKA, MIE YAMAGUCHI, MASAKAZU FUTAOKA, \\ RYOZI HINO \\ Department of Material Science, Faculty of Science and Engineering, \\ Shimane University, Nishikawatsu 1060, Matsue, Shimane 690-8504, Japan
}

\begin{abstract}
Synthetic colloidal calcium hydroxyapatite $\left(\mathrm{Ca}_{10}\left(\mathrm{PO}_{4}\right)_{6}(\mathrm{OH})_{2}\right.$ : Hap) was treated with pyrophosphoric acid $\left(\mathrm{H}_{4} \mathrm{P}_{2} \mathrm{O}_{7}: \mathrm{PP}\right)$ in acetone and the materials were characterized by a variety of techniques. XRD pattern and morphology of Hap particles were essentially not changed by the modification. The additional amount of $\mathrm{PO}_{4}$ of Hap increased with an increase of PP concentration and the $\mathrm{Ca} / \mathrm{P}$ molar ratio of the particles decreased from 1.62 to 0.81 . IR results indicated that the isolated surface $\mathrm{P}-\mathrm{OH}$ band developed with increasing the PP concentration up to $6.0 \mathrm{mmol} \mathrm{dm} \mathrm{dm}^{-3}$ by the reaction of isolated surface $\mathrm{P}-\mathrm{OH}$ groups of Hap and PP. Above $10.2 \mathrm{mmol} \mathrm{dm}^{-3}$, hydrogen-bonding surface $\mathrm{P}-\mathrm{OH}$ band appeared at $2913 \mathrm{~cm}^{-1}$ and enlarged with increasing the PP concentration, while the isolated surface $\mathrm{P}-\mathrm{OH}$ band weakened. The results of $\mathrm{N}_{2}$ and $\mathrm{H}_{2} \mathrm{O}$ adsorption measurement revealed that the modified particles rather aggregated compared to the unmodified ones.
\end{abstract}

\section{INTRODUCTION}

Calcium hydroxyapatite, $\mathrm{Ca}_{10}\left(\mathrm{PO}_{4}\right)_{6}(\mathrm{OH})_{2}$ designated as Hap, is a principal component of hard tissues and has been of interest in industry and medical and dental fields. Synthetic colloidal Hap particles find many applications such as adsorbents for chromatography to separate protein and enzyme, catalysts for dehydration and dehydrogenation of alcohols, methane oxidation, and artificial teeth and bones. ${ }^{1-6}$ These properties relate to various surface properties of Hap, e.g., surface functional groups, acidity and basicity, surface charge, hydrophilicity and porosity. It has been found that the Hap surface possesses ca. 2.6 groups $\mathrm{nm}^{-2}$ of $\mathrm{P}-\mathrm{OH}$ groups acting as the adsorption sites for $\mathrm{CO}_{2}, \mathrm{CH}_{3} \mathrm{OH}, \mathrm{H}_{2} \mathrm{O}, n$-butylamine and acetic acid. ${ }^{7-11}$ Hence, the regulation of number and kinds of surface $\mathrm{P}-\mathrm{OH}$ groups is expected to change the aforementioned properties of Hap. However, to our knowledge, no study has been reported on regulation of surface $\mathrm{P}-\mathrm{OH}$ groups.

The aim of this study was to alter the surface structure and properties of Hap particles by modifying with PP. Therefore, the synthetic colloidal Hap particles were treated with various PP concentrations and the surface nature of the materials were investigated by FTIR, molecular adsorption, XRD, TEM, elemental analysis and so on. 


\section{EXPERIMENTAL}

The colloidal Hap particles were synthesized from a wet method by aging the precipitates formed from the reaction of $\mathrm{Ca}(\mathrm{OH})_{2}$ solutions with $\mathrm{H}_{3} \mathrm{PO}_{4}$ in a sealed Teflon vessel under $\mathrm{CO}_{2}$-free conditions at $100^{\circ} \mathrm{C}$ for $48 \mathrm{~h}$. The $\mathrm{Ca} / \mathrm{P}$ molar ratio of Hap thus prepared was 1.62 , meaning that the material was $\mathrm{Ca}^{2+}$-deficient.

Surface modification of Hap was carried out as follows. One gram of the synthetic Hap particles dried at $140^{\circ} \mathrm{C}$ for $24 \mathrm{~h}$ in an air oven was treated by refluxing in $60 \mathrm{ml}$ of $0-76.8 \mathrm{mmol} \mathrm{dm}{ }^{-3} \mathrm{PP}$ acetone solution at the boiling temperature of the solution for $5 \mathrm{~h}$. The PP-treated particles were filtered off, thoroughly washed with acetone, and finally dried in an air oven at $50^{\circ} \mathrm{C}$ for $24 \mathrm{~h}$. All the chemicals were reagent grade and were used without further purification.

The materials thus obtained were characterized by various techniques. Powder X-ray diffraction (XRD) patterns were taken on a Rigaku diffractometer with a Ni-filtered $\mathrm{CuK} \alpha$ radiation. Particle morphology was observed by a JEOL transmission electron microscope (TEM). Ca and P contents were assayed by a Perkin-Elmer atomic absorption spectrometer (AAS) and a molybdenum blue method, respectively, after dissolving the sample in $\mathrm{HCl}$ solution. Specific surface area was estimated from the $\mathrm{N}_{2}$ adsorption isotherms measured by a Quantumchrome volumetric apparatus at the boiling temperature of liquid nitrogen fitting the BET equation. Adsorption isotherms of $\mathrm{H}_{2} \mathrm{O}$ were determined by a gravimetric technique at $25.0^{\circ} \mathrm{C}$. Transmission IR spectra in vacuo at room temperature were recorded by a self-supporting disk method using a JASCO Fourier transform infrared (FTIR) spectrometer. Before the molecular adsorption and IR measurement, the samples were evacuated at $300^{\circ} \mathrm{C}$ for $2 \mathrm{~h}$.

\section{RESULTS AND DISCUSSION}

\section{Structure of Modified Hap}

The XRD patterns of the modified Hap showed only the peaks due to Hap and no pronounced change on crystallinity was recognized. By the TEM observation, the unmodified particles were rod-shaped and their mean sizes were ca. $70 \mathrm{~nm}$ (length) and ca. $17 \mathrm{~nm}$ (width). The particle morphology and sizes were essentially unchanged by the treatment and no new particles were generated. Figure 1 shows the change of $\mathrm{Ca} / \mathrm{P}$ molar ratio

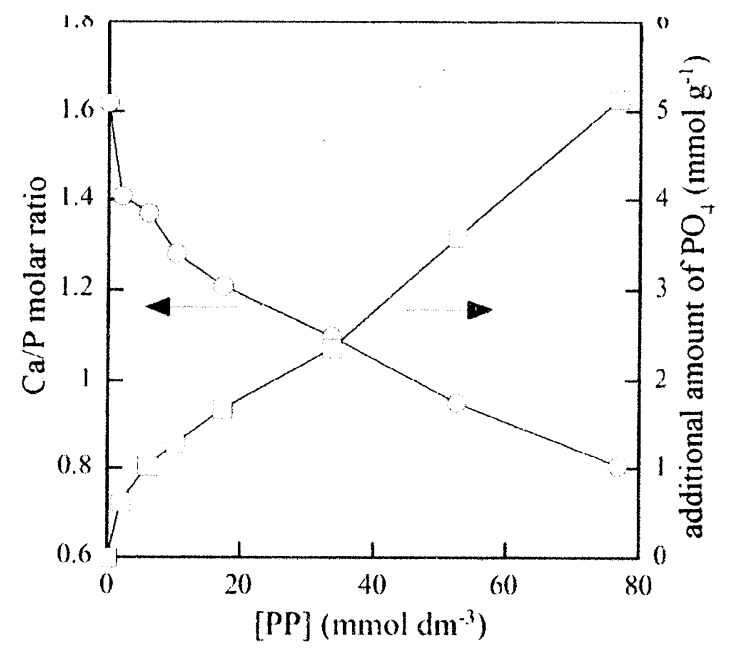

FIGURE 1 Plots of molar ratio $\mathrm{Ca} / \mathrm{P}$ and additional amount of $\mathrm{PO}_{4}$ of Hap against [PP]. 
of the modified Hap against PP concentration. Hereafter, PP concentration is abbreviated as [PP]. The molar ratio $\mathrm{Ca} / \mathrm{P}$ decreases with increasing $[\mathrm{PP}]$. This seems to be due to the increment of $\mathrm{PO}_{4}$ content in the materials, because the dissolution of Hap particles was not confirmed during the treatment. These facts reveal that PP reacts with the particle surface of Hap. To know the modification extent, the additional amount of $\mathrm{PO}_{4}$ on the modified materials was estimated from $\mathrm{Ca}$ and $\mathrm{P}$ contents and was also shown in Fig. 1. Clearly seen, the additional amount of $\mathrm{PO}_{4}$ increases with raising $[\mathrm{PP}]$. The details of modification process will be described later.

\section{Surface Structure of Modified Hap}

In order to explore the surface structure of the modified Hap, IR spectra were taken. Figure 2 shows the IR spectra in vacuo at room temperature of Hap unmodified and modified with different [PP]. Before the measurement, the samples were outgassed at $300^{\circ} \mathrm{C}$ for $2 \mathrm{~h}$. Spectrum of the unmodified Hap possesses a strong absorption band at $3570 \mathrm{~cm}^{-1}$ and a weak one at $3660 \mathrm{~cm}^{-1}$. The former band is due to the $\mathrm{OH}^{-}$ions in the Hap lattice and the latter one to the $\mathrm{O}-\mathrm{H}$ stretching vibration mode of isolated surface $\mathrm{P}-\mathrm{OH}$ groups generated by the protonation of surface $\mathrm{PO}_{4}{ }^{3-}$ ions to maintain the charge balance of Hap particles. ${ }^{7,8}$ In spectrum of the Hap modified at $[\mathrm{PP}]=2.0$ mmol dm${ }^{-3}$, a new band founds at $3670 \mathrm{~cm}^{-1}$. By H-D isotope exchange, this band can be ascribed to the $\mathrm{O}-\mathrm{H}$ stretching vibration modes of additional isolated surface $\mathrm{P}-\mathrm{OH}$ groups formed by the reaction of surface $\mathrm{P}-\mathrm{OH}$ groups of Hap and $\mathrm{PP}$ as follow:

$$
\mathrm{P}-\mathrm{OH} \text { (surface) }+\mathrm{H}_{4} \mathrm{P}_{2} \mathrm{O}_{7} \rightarrow \text { P-O-PO }(\mathrm{OH})_{2} \text { (surface) }+\mathrm{H}_{3} \mathrm{PO}_{4}-(1)
$$

Besides, the additional surface $\mathrm{P}-\mathrm{OH}$ groups formed also react with $\mathrm{PP}$ as follow :

$$
\begin{gathered}
\mathrm{P}-\mathrm{O}-\mathrm{PO}(\mathrm{OH})_{2}(\text { surface })+\mathrm{H}_{4} \mathrm{P}_{2} \mathrm{O}_{7} \rightarrow \\
\mathrm{P}-\mathrm{O}-\mathrm{PO}(\mathrm{OH})-\mathrm{O}-\mathrm{PO}(\mathrm{OH})_{2} \text { (surface) }+\mathrm{H}_{3} \mathrm{PO}_{4}-(2)
\end{gathered}
$$

Note that the number of surface $\mathrm{P}-\mathrm{OH}$ groups formed by the reactions (1) and (2) corresponds to additional amount of $\mathrm{PO}_{4}$ of the materials, meaning that the number of surface $\mathrm{P}-\mathrm{OH}$ groups of Hap increases with increasing the additional amount of $\mathrm{PO}_{4}$. When the materials are modified at $[\mathrm{PP}] \leq 6.0$ $\mathrm{mmol} \mathrm{dm}^{-3}$, the isolated surface $\mathrm{P}-\mathrm{OH}$ band develops with an increase of [PP]. Interestingly, this band steeply weakens at $[\mathrm{PP}]=6.0$ mmol $\mathrm{dm}^{-3}$. Furthermore, a new broad band centered at $2913 \mathrm{~cm}^{-1}$

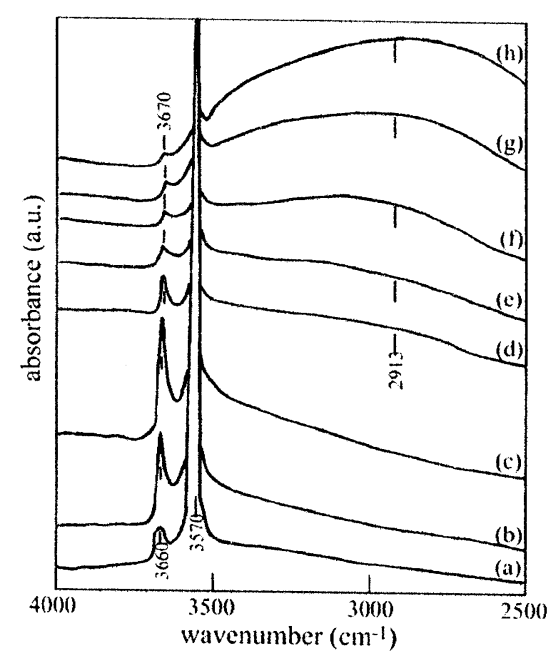

FIGURE 2 IR spectra in vacuo of Hap modified with various $[\mathrm{PP}]$. [PP] $\left(\mathrm{mmol} \mathrm{dm}^{-3}\right)$ : (a) 0 , (b) 2.0 , (c) 6.0 , (d) 10.2 , (e) 17.3 , (f) 33.7 , (g) 52.6 , (h) 76.8 . 
appears at $[\mathrm{PP}]=10.2 \mathrm{mmol} \mathrm{dm}$ and the band enlarges on raising [PP]. To get further insight into these bands, Figure 3 plots the area intensity of isolated surface $\mathrm{P}-\mathrm{OH}$ and $2913 \mathrm{~cm}^{-1}$ bands as a function of $[\mathrm{PP}]$. On modifying at $[\mathrm{PP}] \leq 6.0$ $\mathrm{mmol} \mathrm{dm}^{-1}$, the area intensity of isolated surface $\mathrm{P}-\mathrm{OH}$ band steeply rises with increasing [PP]. Modifying at $[\mathrm{PP}]=10.2 \mathrm{mmol} \mathrm{dm}^{-3}$ increases the intensity of $2913 \mathrm{~cm}^{-1}$ band and suddenly reduces the intensity of isolated surface $\mathrm{P}-\mathrm{OH}$ band. At $[P P] \geq 10.2 \mathrm{mmol} \mathrm{dm}^{-3}$, the

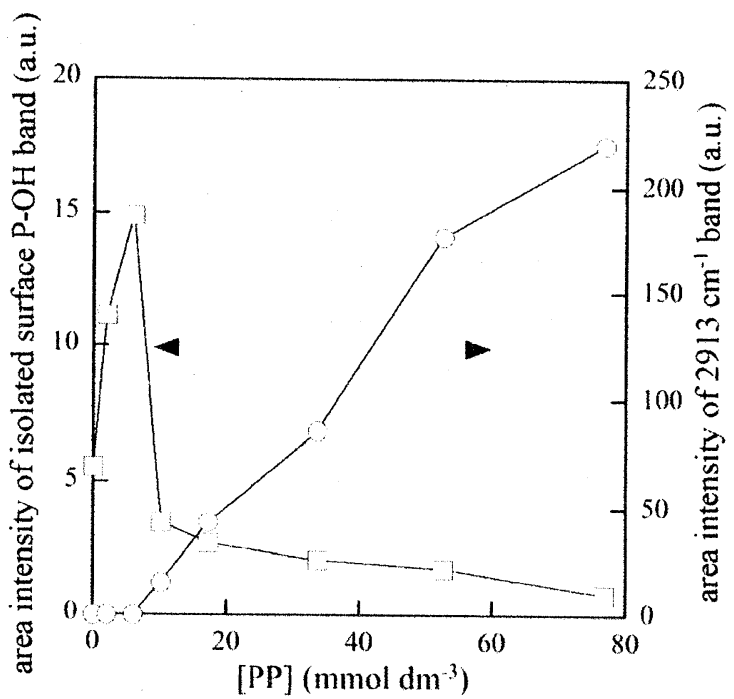

FIGURE 3. Plots of area intensities of isolated surface $\mathrm{P}-\mathrm{OH}$ and $2913 \mathrm{~cm}^{-1}$ bands vs. [PP].

$2913 \mathrm{~cm}^{-1}$ band further intensifies,

while the isolated surface $\mathrm{P}-\mathrm{OH}$ band slightly decreases. The foregoing results imply that the state of surface $\mathrm{P}-\mathrm{OH}$ groups is altered at $[\mathrm{PP}] \geq 10.2 \mathrm{mmol} \mathrm{dm}^{-3}$. To assign the $2913 \mathrm{~cm}^{-1}$ band, H-D exchange of unmodified and modified materials was examined by IR spectroscopy. For the unmodified Hap, the isolated surface $\mathrm{P}-\mathrm{OH}$ band weakened with the H-D exchange and the isolated surface P-OD and OD bands were found at 2702 and $2630 \mathrm{~cm}^{-1}$, respectively (not shown here). In case of Hap modified at $[\mathrm{PP}]=52.6 \mathrm{mmol} \mathrm{dm}^{-3}$, the isolated surface $\mathrm{P}-\mathrm{OH}$ band slightly weakened with H-D exchange and the isolated surface P-OD band at $2710 \mathrm{~cm}^{-1}$ and $\mathrm{OD}^{-}$band at $2630 \mathrm{~cm}^{-1}$ appeared as well as the unmodified Hap. Besides these bands, a broad band at $2913 \mathrm{~cm}^{-1}$ weakened and a new broad band developed at $2160 \mathrm{~cm}^{-1}$. The wavenumber ratio of 2913 and $2160 \mathrm{~cm}^{-1}$ bands is 1.349 , close to $1.354-1.355$ of the isolated surface P-OH/P-OD (3660/2702, 3670/2710) and lattice $\mathrm{OH}^{-} / \mathrm{OD}^{-}(3570 / 2630)$ detected on unmodified and modified Hap and 1.374 of the theoretical $v_{\mathrm{OH}} / v_{\mathrm{OD}}$ ratio. These facts allow us to infer that a broad band centered at $2913 \mathrm{~cm}^{-1}$ is assigned to the surface $\mathrm{P}-\mathrm{OH}$ groups. Low and Ramamurthy indicated by IR measurement of phosphoric acid impregnated silica gel that a broad band at ca. $3000 \mathrm{~cm}^{-1}$ is due to the hydrogen-bonding surface P-OH groups. ${ }^{12}$ The position of the $2913 \mathrm{~cm}^{-1}$ band detected in the present study almost corresponds to that of ca. $3000 \mathrm{~cm}^{-1}$ band of surface hydrogen-bonding P-OH groups. From these results, the broad $2913 \mathrm{~cm}^{-1}$ band observed in Fig. 2 can be assigned to the hydrogen-bonding surface $\mathrm{P}-\mathrm{OH}$ groups. The formation of the $2913 \mathrm{~cm}^{-1}$ band can be explained by considering that the number and density of surface $\mathrm{P}-\mathrm{OH}$ groups of Hap increase after modifying with $[\mathrm{PP}] \geq 10.2$ mmol $\mathrm{dm}^{-3}$, resulting in the adjacent additional hydrogen-bonding surface $\mathrm{P}-\mathrm{OH}$ groups. 


\section{Adsorption of $\mathrm{N}_{2}$ and $\mathrm{H}_{2} \mathrm{O}$}

We measured the adsorption isotherms of $\mathrm{N}_{2}$ on unmodified and modified Hap. Before the adsorption, the samples were outgassed at $300^{\circ} \mathrm{C}$ for $2 \mathrm{~h}$. All the isotherms belonged to type II in the IUPAC classification. The amount of $\mathrm{N}_{2}$ adsorbed gradually decreased with increasing [PP]. Figure 4 plots the specific surface area $\left(\mathrm{SN}_{2}\right)$ estimated from the $\mathrm{N}_{2}$ adsorption isotherms fitting the BET equation against [PP]. The $\mathrm{SN}_{2}$ monotonously decreases on raising [PP]. As indicated above, the surface hydrogen-bonding $\mathrm{P}-\mathrm{OH}$ groups are formed on Hap at $[\mathrm{PP}] \geq 10.2 \mathrm{mmol} \mathrm{dm}{ }^{-3}$. It can be, therefore, inferred that the hydrogen-bond of $\mathrm{P}-\mathrm{OH}$ groups is generated not only on primary Hap particles but also among the aggregated particles. As a result, the modified Hap particles seem to more aggregate than the unmodified ones, leading to the reduction in effective surface area available for $\mathrm{N}_{2}$ adsorption.

To confirm this, the $\mathrm{H}_{2} \mathrm{O}$ adsorption isotherms on unmodified and modified Hap were measured and monolayer adsorption capacity of $\mathrm{H}_{2} \mathrm{O}$ molecules per unit surface area obtained by $\mathrm{N}_{2}$ adsorption $\left(\mathrm{n}_{\mathrm{w}}\right)$ is plotted against [PP] in Fig. 4. The $n_{w}$ of the materials modified at $[\mathrm{PP}] \leq 6.0$ $\mathrm{mmol} \mathrm{dm^{-3 }}$ is close to 9.3 molecules $\mathrm{nm}^{-2}$ of theoretical $\mathrm{n}_{\mathrm{w}}$, estimated using $0.108 \mathrm{~nm}^{2}$ as the cross-sectional area of a $\mathrm{H}_{2} \mathrm{O}$ molecule, depicted by a dotted line in this Figure. The $\mathrm{n}_{\mathrm{w}}$ steeply rises to ca. 25 molecules $\mathrm{nm}^{-2}$ at $[\mathrm{PP}]=10.3$ - $33.7 \mathrm{mmol} \mathrm{dm}^{-3}$ and then slightly increases. These facts strongly indicate that the modified particles rather aggregate compared to the unmodified ones and that the ultramicropores form among the particles which can accept $\mathrm{H}_{2} \mathrm{O}$ molecules but not $\mathrm{N}_{2}$ molecules.

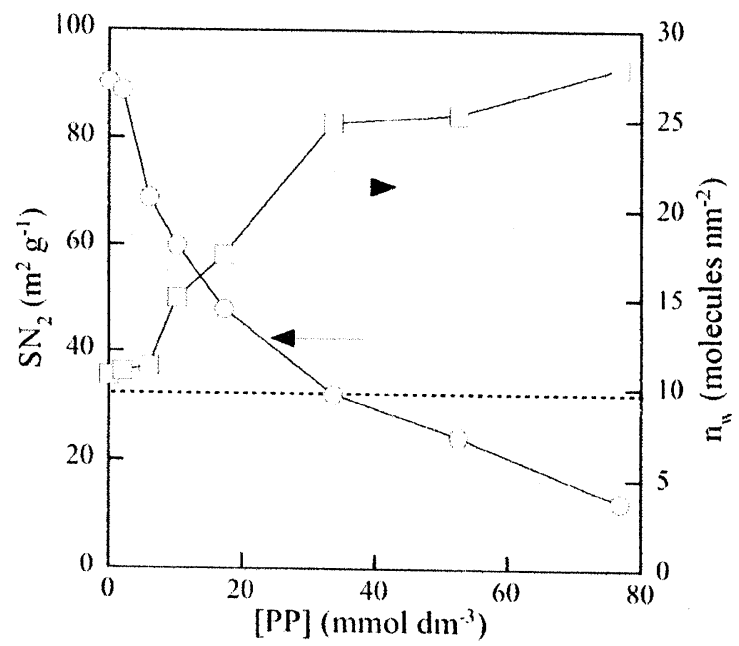

FIGURE 4. Plots of specific surface area $\left(\mathrm{SN}_{2}\right)$ and monolayer adsorption capacity of $\mathrm{H}_{2} \mathrm{O}$ molecules $\left(\mathbf{n}_{\mathrm{w}}\right)$ for the modified Hap vs. [PP].

\section{CONCLUSIONS}

The results obtained in this study can be summarized as follows. The PP molecules react with surface $\mathrm{P}-\mathrm{OH}$ groups of Hap to yield additional surface $\mathrm{P}-\mathrm{OH}$ groups. Raising the $[\mathrm{PP}]$ increases the additional amount of $\mathrm{PO}_{4}$ and number of surface $\mathrm{P}-\mathrm{OH}$ groups of Hap. The particle morphology was essentially not altered during the modification. At $[\mathrm{PP}] \leq 6.0 \mathrm{mmol} \mathrm{dm}^{-3}$, the isolated surface $\mathrm{P}-\mathrm{OH}$ band of Hap 
developed with an increase of [PP]. The hydrogen-bonding surface $\mathrm{P}-\mathrm{OH}$ band appeared at $[P P] \geq 10.2 \mathrm{mmol} \mathrm{dm}^{-3}$ and was intensified by increase in the $[\mathrm{PP}]$. While the isolated surface $\mathrm{P}-\mathrm{OH}$ band was weakened. The modified Hap particles rather aggregate than the unmodified ones. This fact explained by the formation of hydrogen-bonding surface $\mathrm{P}-\mathrm{OH}$ groups among the particles. This was further supported by $\mathrm{N}_{2}$ and $\mathrm{H}_{2} \mathrm{O}$ adsorption measurement.

\section{ACKNOWLEDGMENT}

The authors are grateful to Dr. Kazuhiko Kandori and Professor Tatsuo Ishikawa of Osaka University of Education for their help with TEM observation.

\section{REFERENCES}

1. J. C. Elliott, Structure and Chemistry of the Apatites and Other Calcium Orthophosphates, Elsevier, Amsterdam, 1994.

2. R. Z. LeGeros, in Hydroxyapatites and Related Materials, P. W. Brown and B. Constanz (Eds.), CRC Press, London, 1994, p. 3.

3. J. A. S. Bett, L. G. Christner and W. K. Hall, J. Am. Chem. Soc., 89, 5535(1967).

4. S. Sugiyama, T. Minami, T. Moriga, H. Hayashi, K. Koto, M. Tanaka and J. B. Moffat, J. Mater. Chem., 6, 459 (1996).

5. Y. Matsumura, H. Kanai and J. B. Moffat, J. Chem. Soc., Faraday Trans., 93, 4383 (1997).

6. F. Monroe, W. Votava, D. B. Bass and J. McMullen, J. Dent. Res., 50, 860 (1971).

7. T. Ishikawa, M. Wakamura and S. Kondo, Langmuir, 5, 140 (1989).

8. T. Ishikawa, in Adsorption on New and Modified Inorganic Sorbents, A. Dabrowski and V. A. Terthykh (Eds.), Elsevier Science, Amsterdam, 1996, p. 301.

9. H. Tanaka, in Encyclopedia of Colloid and Surface Science, A. Hubbard (Ed), Marcel Dekker, New York, 2002, p. 5096.

10. H. Tanaka, T. Watanabe and M. Chikazawa, J. Chem. Soc. Faraday Trans., 93, 4377 (1997).

11. H. Tanaka, M. Chikazawa, K. Kandori and T. Ishikawa, Phys. Chem. Chem. Phys., 2. 2647 (2000).

12. M. J. D. Low and P. D. Ramamurthy, J. Phys. Chem., 72, 3161 (1968). 